\title{
Improvement of Psychological Symptoms After Replacement Therapy With Levothyroxine in Hypothyroidism: A Report of 2 Cases
}

\author{
Reza Bidaki ${ }^{1,2}$, Bita Tavana ${ }^{3 *}$, Shima Hosseini ${ }^{4}$, Negar Neshati $^{5}$, Mojtaba Babaei Zarch ${ }^{5}$ \\ ${ }^{1}$ Research Center of Addiction and Behavioral Sciences, Shahid Sadoughi University of Medical Sciences, Yazd, Iran \\ ${ }^{2}$ Diabetes Research Center, Shahid Sadoughi University of Medical Sciences, Yazd, Iran \\ ${ }^{3}$ Sports Medicine Research Center, Neuroscience Institute, Tehran University of Medical Sciences, Tehran, Iran \\ ${ }^{4}$ Kharazmi University, Tehran, Iran \\ ${ }^{5}$ School of Medicine, Shahid Sadoughi University of Medical Sciences, Yazd, Iran
}

*Corresponding Author: Bita Tavana, M.D., No.7, Al-e Ahmad Highway, Sports Medicine Research Center, Neuroscience Institute, Tehran University of Medical Sciences, Tehran, Iran. Tel: +98-21-88630227, Fax: +98-21-88003539, Email: b-tavana@farabi.tums.ac.ir

Received August 20, 2018; Accepted January 29, 2019; Online Published February 16, 2019

\begin{abstract}
Introduction: Hypothyroidism is a common disorder of the endocrine system in which the production of thyroid hormones is inadequate. In addition to various physical manifestations, patients who suffer from hypothyroidism may also present with psychological problems, as described in previous studies.

Case Presentation: Herein, the reports of 2 patients who suffered from hypothyroidism and experienced improvement in their psychological symptoms after levothyroxine therapy are presented. The patients referred with depressive mood with psychotic features and psychomotor retardation. Treatment simultaneously with psychopharmacotherapy and hormone therapy was considered.

Conclusion: Although hypothyroidism and depressive disorders are separate issues, hypothyroidism can induce depression and psychosis, and psychopharmacotherapy plus hormone therapy can be effective and boost treatment.

Keywords: Hypothyroidism, Persecutory Delusion, Psychological Disturbance
\end{abstract}

\section{Introduction}

Hypothyroidism, a common disorder among the general population, includes several physical problems and a variety of psychological disturbances. The disease involves the central as well as peripheral nervous systems. ${ }^{1}$ The psychological symptoms of the disease include depressed mood and impaired memory and concentration; the psychotic symptoms include paranoid delusion, reference delusion, misidentification, visual and auditory hallucinations, and thought disorder. However, these symptoms occur in less than $5 \%$ of all hypothyroidism patients, and they follow the appearance of physical symptoms. ${ }^{2}$ In this study, we introduce 2 patients who suffered from hypothyroidism and whose psychological symptoms were improved after levothyroxine therapy.

\section{Case Presentations}

2.1. Case 1

The patient is a 46-year-old man. He is a rural farmer, married, and has 3 children. Approximately 6 months prior to his initial visit, he found his 20 -year-old son watching a movie with a sexual theme on a website, gradually developed negative feelings toward his spouse, and believed she was in contact with another person. He saw his wife naked, and after that, he regularly argued with her and barred her from contact with the outside. He woke his wife at night forcing her to reveal with whom she was in contact. Several times he attempted to strangle her. He had week sexual, job and interpersonal relationship performance, fatigue and frustration. He had no insight into his problems and did not accept his illness. His wife felt helpless, intimated she would file for divorce, and insisted on referring him to a psychiatrist.

Under examination, the patient exhibited a puffy face (myxedema) and psychomotor retardation. He had no previous history of a psychiatric disorder. The symptoms were severe and accelerating. Vital signs included a pulse rate of 62 beats/min and blood pressure of 130/80

Copyright $\odot 2019$ The Author(s). This is an open-access article distributed under the terms of the Creative Commons Attribution License (http:// creativecommons.org/licenses/by/4.0), which permits unrestricted use, distribution, and reproduction in any medium, provided the original work is properly cited. 
$\mathrm{mm} \mathrm{Hg}$. The following drugs were prescribed for the patient: levothyroxine $0.1 \mathrm{mg} \mathrm{QD}$, risperidone $2 \mathrm{mg}$ at night, citalopram $20 \mathrm{mg}$ daily, haloperidol $0.5 \mathrm{mg}$ BID, and trihexyphenidyl $2 \mathrm{mg} 1 / 2 \mathrm{tab}$ BID. Laboratory tests revealed $\mathrm{TG}=460$, cholesterol $=380$, and $\mathrm{TSH}>25$. Based on the existence of clinical symptoms of hypothyroidism and the matching clinical examination, treatment of the delusional disorder, the jealousy type (jealousy delusion), with depression was begun for the patient. Unfortunately, 3 days after starting treatment, the patient discontinued the medication. A month later he was forced to be referred to a psychiatrist with symptoms more severe than the first time. He had depressed mood, frequent crying, feeling duality towards his wife expressed in the form of love and hate. The above-mentioned drugs were started again, and the patient was hospitalized. After fifteen days hospitalization and a reduction in his symptoms, he was discharged. The patient experienced only partial delusions, the intensity of his depressed mood decreased, and his symptoms completely vanished over the following five months in which five monthly follow-up visits were conducted. The patient's thyroid tests became normal, and his fatigue, weakness, and reduced energy levels faded.

\subsection{Case 2}

This patient is a young man, about 22 years old, he did like be a rich person and have multiple expensive cars from childhood period. There was no previous history of psychiatric disorder in him or his family. He was first referred to a psychiatrist by his family, but he refused to take the prescribed medication. Ultimately, he was hospitalized. Psychomotor retardation, amotivation, abulia, depressed mood, dreams of having sports cars, as well as mental images of a fantasy world, poor attention to personal grooming, poor eye contact, refusing to take medications, and having pessimistic thoughts about his father (whom he blamed for all his problems) were identified as signs in this patient. After 3 weeks, the patient experienced a reduction in symptoms and was discharged from the hospital. The intensity of his depressed mood had decreased, but the dreams continued during the 2 months of follow up (5 sessions). Fluoxetine $20 \mathrm{mg}$ daily was prescribed in the first week and increased to $40 \mathrm{mg}$ in the second week. The symptoms were severe and accelerating. Due to psychomotor retardation, bupropion $75 \mathrm{mg}$ was prescribed. Resperidon $1 \mathrm{mg}$ every night was also prescribed and then increased to $2 \mathrm{mg}$ in 3 days. Additionally, trihexyphenidyl $2 \mathrm{mg}$ was prescribed. After 3 days, the patient exhibited a dramatic response to the medication. Laboratory tests and MRI results were normal. Interestingly, the rate of TSH was 40 , so levothyroxine $0.1 \mathrm{mg}$ daily was begun. The patient's thyroid increased in size. The patient complained of having a puffy face, hair loss, and coldness in his extremities. The first diagnosis was depressive disorder with psychotic features due to hypothyroidism.

At the present time, the patient is asymptomatic, but he is still a dreamer and ambitious with no tendency to work; he is called a lazy and arrogant person at home.

The aim of introducing the preceding 2 cases was to show a psychotic disorder and a depressive disorder with psychotic features followed by an organic disorder, such as hypothyroidism, as well as the parallel psychotic and hypothyroidism treatment terminating with appropriate results. In older literature, one can see a diagnosis of "schizophrenia aneroid", a case in which the patient lives in a visionary and fantasy world; it is not pointless to refer to such perspective here.

\section{Discussion}

Although the relationship between hypothyroidism and depression has been previously confirmed, the nature of this relationship has not been convincingly demonstrated. ${ }^{3}$ Two large, epidemiological studies comprising 30000 samples $^{4}$ and 6869 samples $^{5}$ stated that there is no relationship between thyroid function and depression in people with normal thyroids..$^{3-7}$ One study conducted by Panicker et $\mathrm{al}^{8}$ demonstrated that higher TSH is associated with a lower rate of depression in males. This shows the possibility of ignoring increased TSH as a major reason for depression in males, and the roles of other factors should be considered. As hypothyroidism is more common in female sex and less attention is about it. Therefore, it maybe misdiagnosed in clinical practice. The rate of TSH was very high for both patients. It seems that the prolongation of a medical disease and its severity can predict the severity of psychiatric disorders. Failure to diagnose hypothyroidism can cause exacerbation and prolongation of psychiatric disorders.

The relationship between thyroid function and depression in patients taking thyroxin was first shown by Saravanan et al. ${ }^{9}$ They noticed a relationship between higher TSH rates and lower free T4 levels as well as poorer well-being in 697 cases undergoing thyroxin therapy in the United States.

These findings are compatible with the findings of studies conducted by Panicker et $\mathrm{al}^{8}$ and Wekking et al. ${ }^{10}$ Psychiatric patients may have abnormal thyroid function. ${ }^{11,12}$ Moreover, the prevalence of myxedematous madness was $26 \%{ }^{12}$ and approximately $50 \%{ }^{13}$ in 1920 and the late 1800s, respectively. Hallucination and delusion occur in almost half of the patients, particularly at more advanced stages of the disease. ${ }^{13}$ Both patients discussed herein had positive symptoms (hallucination and delusion). The older patient also had jealousy delusions, like a delusional disorder. The vegetative symptoms were dominant, too. There was no diagnosis in Axis II.

Patients with thyroid dysfunction experience extensive neurotic-medical manifestations, which can lead to a diagnosis of mild hypothyroidism.

Long-term hypothyroidism may result in a permanent cognitive deficiency originating from the death of neural cells caused by thyroid problems in the brain. ${ }^{2}$ There is the likelihood of a lack of any clinical manifestations for this severe hypothyroidism. ${ }^{14}$ As a result, it is important to note 
that many patients with psychological manifestations may have changes in the function of the endocrine system. ${ }^{15}$ Nevertheless, there is evidence that genetic factors can also affect proper thyroxin function as well as responses to combination therapy and need further study.

\section{Conclusion}

Although depressive disorders and hypothyroidism are separate issues, the augmentation of therapy with both antipsychotics and levothyroxine can lead to clinical improvement.

\section{Authors' Contributions}

$\mathrm{RB}$ visited and followed the patients. BT, $\mathrm{SH}, \mathrm{MBZ}$ and $\mathrm{RB}$ wrote the manuscript. The manuscript was revised by NN and $\mathrm{RB}$.

\section{Conflict of Interest Disclosures}

The authors declare that they have no conflicts of interest.

\section{Ethical Approval}

The patients and their families gave permission for the presentation of their case reports.

\section{References}

1. Ferreira AC, Caldeira M, Fraga C. Hypothyroidism Presenting as Psychosis: Myxedema Madness Revisited. Eur J Intern Med. 2011;22 Suppl 1:S15. doi:10.1016/S0953-6205(11)60058-7.

2. Rao AC, Bhat VK, Kini S. Myxoedema presenting with psychosis. Indian J Psychiatry. 1990;32(3):287-289.

3. Dayan CM, Panicker V. Hypothyroidism and depression. Eur Thyroid J. 2013;2(3):168-179. doi:10.1159/000353777.

4. Engum A, Bjoro T, Mykletun A, Dahl AA. An association between depression, anxiety and thyroid function--a clinical fact or an artefact? Acta Psychiatr Scand. 2002;106(1):27-34. doi:10.1034/j.1600-0447.2002.01250.x.

5. Forman-Hoffman V, Philibert RA. Lower TSH and higher T4 levels are associated with current depressive syndrome in young adults. Acta Psychiatr Scand. 2006;114(2):132-139. doi:10.1111/j.1600-0447.2005.00703.x.

6. Roberts LM, Pattison H, Roalfe A, et al. Is subclinical thyroid dysfunction in the elderly associated with depression or cognitive dysfunction? Ann Intern Med. 2006;145(8):573-581. doi:10.7326/0003-4819-145-8-200610170-00006.

7. Almeida OP, Alfonso H, Flicker L, Hankey G, Chubb SA, Yeap BB. Thyroid hormones and depression: the Health in Men study. Am J Geriatr Psychiatry. 2011;19(9):763-770. doi:10.1097/ JGP.0b013e31820dcad5.

8. Panicker V, Evans J, Bjoro T, Asvold BO, Dayan CM, Bjerkeset $O$. A paradoxical difference in relationship between anxiety, depression and thyroid function in subjects on and not on T4: findings from the HUNT study. Clin Endocrinol (Oxf). 2009;71(4):574-580. doi:10.1111/j.1365-2265.2008.03521.x.

9. Saravanan P, Visser TJ, Dayan CM. Psychological well-being correlates with free thyroxine but not free 3,5,3'-triiodothyronine levels in patients on thyroid hormone replacement. J Clin Endocrinol Metab. 2006;91(9):3389-3393. doi:10.1210/ jc.2006-0414.

10. Wekking EM, Appelhof BC, Fliers E, et al. Cognitive functioning and well-being in euthyroid patients on thyroxine replacement therapy for primary hypothyroidism. Eur J Endocrinol. 2005;153(6):747-753. doi:10.1530/eje.1.02025.

11. Whynbrow PC, Bauer M. Behavioral and psychiatric aspects of thyrotoxicosis. In:Braverman LE, Utiger RD, eds. Werner \& Ingbar's The Thyroid: A Fundamental and Clinical Textbook. Philadelphia, Pennsylvania: Lippincott Williams \& Wilkins; 2000:673-678.

12. Whynbrow PC. Behavioral and psychiatric aspects of hypothyroidism. In: Braverman LE, Utiger RD, eds. Werner \& Ingbar's The Thyroid: A Fundamental and Clinical Textbook. Philadelphia, Pennsylvania: Lippincott Williams \& Wilkins; 2000:837-842.

13. The Clinical Society of London. Report of acommittee to investigate the subject of myxoedema. Trans Clin Soc London. 1888;21(suppl):1-215.

14. Reed K, Bland RC. Masked "myxedema madness". Acta Psychiatr Scand. 1977;56(5):421-426. doi:10.1111/j.1600-0447.1977. tb06682.x.

15. Dastjerdi G. Delusional type psychosis associated with hypothyroidism: A case report. Procedia Soc Behav Sci. 2013;84:1050-1052. doi:10.1016/j.sbspro.2013.06.697. 